\title{
BMJ Open Assessing efficacy of CytoSorb haemoadsorber for prevention of organ dysfunction in cardiac surgery patients with infective endocarditis: REMOVE- protocol for randomised controlled trial
}

\author{
Mahmoud Diab (D) , ${ }^{1,2}$ Stephanie Platzer, ${ }^{2}$ Albrecht Guenther, ${ }^{3}$ \\ Christoph Sponholz (D) , ${ }^{4}$ Andre Scherag (D) , ${ }^{2,5,6}$ Thomas Lehmann, ${ }^{2}$ Ilia Velichkov, ${ }^{1}$ \\ Stefan Hagel, ${ }^{2,7}$ Michael Bauer, $^{2,4}$ Frank M Brunkhorst, ${ }^{2,4,5}$ Torsten Doenst $^{1}$
}

To cite: Diab M, Platzer S, Guenther A, et al. Assessing efficacy of CytoSorb haemoadsorber for prevention of organ dysfunction in cardiac surgery patients with infective endocarditis: REMOVEprotocol for randomised controlled trial. BMJ Open 2020;10:e031912. doi:10.1136/ bmjopen-2019-031912

- Prepublication history and additional material for this paper are available online. To view these files, please visit the journal online (http://dx.doi. org/10.1136/bmjopen-2019031912).

Received 27 May 2019 Revised 25 November 2019 Accepted 05 March 2020
Check for updates

(C) Author(s) (or their employer(s)) 2020. Re-use permitted under CC BY-NC. No commercial re-use. See rights and permissions. Published by BMJ.

For numbered affiliations see end of article.

Correspondence to

Dr Torsten Doenst;

Doenst@med.uni-jena.de

\section{ABSTRACT}

Introduction Infective endocarditis (IE) is associated with high mortality and morbidity. Multiple organ failure is the main cause of death after surgery for IE. Cardiopulmonary bypass (CPB) can cause a systemic inflammatory response. In a pilot study (REMOVE-pilot (Revealing mechanisms and investigating efficacy of hemoad-sorption for prevention of vasodilatory shock in cardiac surgery patients with infective endocarditis - a multicentric randomized controlled group sequential trial)), we found that plasma profiles of cytokines during and after CPB were higher in patients with IE compared with patients with non-infectious valvular heart disease. Sequential Organ Failure Assessment (SOFA) scores on the first and second postoperative days and in-hospital mortality were also higher in IE patients. This protocol describes the design of the REMOVE trial on cytokine-adsorbing columns, for example, CytoSorb, for nonselective removal of cytokines. The aim of the REMOVE study is to demonstrate efficacy of CytoSorb on the prevention of multiorgan dysfunction in patients with IE undergoing cardiac surgery.

Methods and analysis The REMOVE study is an interventional randomised controlled multicenter trial with a group sequential (Pocock) design for assessing efficacy of CytoSorb in patients undergoing cardiac surgery for IE. The change in mean total SOFA ( $\triangle$ SOFA) score between preoperative and postoperative care will be used as primary endpoint. Data on 30-day mortality, changes in cytokines levels, duration of mechanical ventilation, length of intensive care unit and hospital stay, and postoperative stroke will be collected as secondary endpoints. An interim analysis will be conducted after including 25 participating patients per study arm (with a focus on feasibility of the recruitment as well as differences in cytokines and cell-free DNA levels).

Ethics and dissemination The protocol was approved by the institutional review board and ethics committee of the University of Jena as well as by the corresponding ethics committee of each participating study centre. The results will be published in a renowned international medical journal, irrespective of the outcomes of the study.

Trial registration number The ClinicalTrials.gov registry (NCT03266302).

\section{Strengths and limitations of this study}

- The topic of the study is clinically relevant, as the mortality after surgery for infective endocarditis (IE) is still very high and there is a need for new treatment modalities.

- Strict patient selection guided by the modified Duke Criteria for the diagnosis of IE; low-risk patients with EuroSCORE $\| \leq 3$ will be excluded.

- This is the first randomised multicenter study assessing the efficacy of CytoSorb in patients with infective endocarditis undergoing cardiac surgery.

- The primary endpoint chosen in this study is the $\Delta$ mean total Sequential Organ Failure Assessment Score which has been used in a number of previous clinical trials in sepsis.

- The study is not blinded; however, we are not expecting that to cause bias, because the primary endpoint is calculated based on clinical and laboratory parameters which are routinely measured in the intensive care unit.

\section{INTRODUCTION}

Infective endocarditis (IE) affects 1-10/100 000 persons per year worldwide and is associated with up to $40 \%$ in-hospital mortality. ${ }^{1-3}$ Surgical treatment is necessary in about $50 \%$ of patients and is associated with in-hospital mortality as high as $15 \%-25 \%$ and 1-year mortality of $40 \% .{ }^{14}$ The postoperative course of patients with IE is often complicated with a varying degree of circulatory failure, that is, hypotension, decreased systemic vascular resistance, despite high cardiac output, adequate fluid resuscitation and adrenergic vasopressor administration which can progress to septic shock in up to $10 \%-28 \%$ of cases. ${ }^{5-7}$ If septic shock complicates the course of the disease mortality can reach up 
Q Endocarditis $\square \mathrm{VHD}$

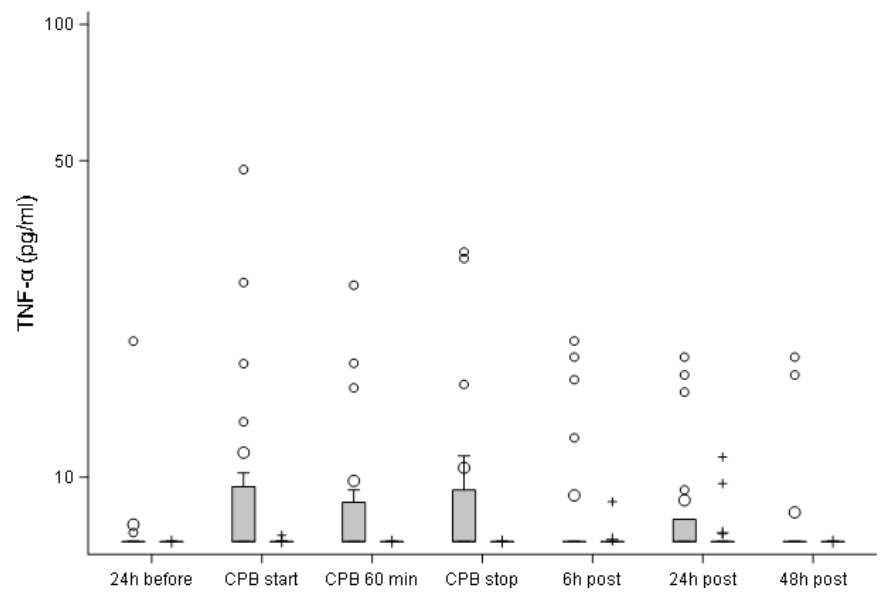

Figure 1 Boxplots of TNF- $\alpha$ plasma concentrations before, during and after cardiac surgery in patients with infective endocarditis and valvular heart disease. ${ }^{15}$ Before, before surgery; CPB, cardiopulmonary bypass; post, after surgery; TNF, tumour necrosis factor; VHD, valvular heart disease.

to $75 \%-100 \%$ in some studies. ${ }^{78}$ We previously showed that septic shock leading to multiple organ failure was the main cause of death in $78.7 \%$ of patients who died after surgical procedures for IE. ${ }^{9}$

The mechanism of circulatory failure complicating the postoperative course of endocarditis has not been completely elucidated. Some presumed mechanisms include a combination of endothelial injury, argininevasopressin-system dysfunction and release of vasodilatatory mediators. ${ }^{10}$ The mechanism that triggers septic shock in IE patients is also not fully understood and warrants further investigation. ${ }^{11}$ Interleukin-6 (IL-6), IL-8, IL-18 and IL-1 $\beta$ are proinflammatory cytokines participating in the development of the innate immunity and are associated with unfavourable outcome in severe sepsis. ${ }^{12}$ However, available information on the role of these cytokines in IE is scarce. Bustamante et al reported elevated IL-6, IL-8 and interferon- $\gamma$ (IFN- $\gamma$ ) plasma levels to be associated with an unfavourable outcome in patients with prosthetic-valve IE. ${ }^{13}$ In addition, Ekdahl $e t$ $a l$ investigated human valves from IE patients for the presence of IL-8 and tumour necrosis factor-alpha (TNF- $\alpha$ ) containing cells. They suggested the local occurrence of IL-8 containing cells as a potential marker of disease activity. ${ }^{14} \mathrm{~A}$ further potential mechanism of postoperative circulatory failure and septic shock may be related to the liberation of infective material at the time of surgical removal of the infected tissues.

Surgery using cardiopulmonary bypass (CPB) initiates a systemic inflammatory response induced by extrinsic (eg, anaesthesia, contact activation within the extracorporeal circuit and endotoxemia) and intrinsic (eg, tissue damage, endothelial cell activation and ischaemia-reperfusion injury of the myocardium) factors. All of these factors may delay weaning from the ventilator, recovery of organ function and discharge from intensive care unit (ICU) and increase perioperative mortality. Thus measures to decrease the inflammatory process have the potential to improve the perioperative outcome.

As part of the preparatory work for this study, we performed a case-control pilot study. ${ }^{15}$ We investigated the release profiles of inflammatory and vasoactive mediators before, during and after cardiac surgery in patients with IE as well as in patients with non-infectious valvular heart disease (VHD). We found that plasma profiles of cytokines during and after CPB were significantly higher in patients with IE than in patients with non-infectious VHD. Figure 1 shows that TNF- $\alpha$ levels increased rapidly after CPB initiation in the IE group, while in the VHD group it was not detectable. Sequential Organ Failure Assessment (SOFA) scores on the first and second postoperative days were higher in IE group than the VHD group. In addition, in-hospital mortality was higher in the IE group (35\%) than in VHD group $(5 \%)$.

Cytokine-adsorbing columns, for example, CytoSorb, are specifically designed for the non-selective removal of cytokines. They are composed of beads that are able to capture and adsorb cytokines by size exclusion chromatography and non-selective hydrophobic interactions. Small molecules, below $5 \mathrm{kDa}$, travel through the pores of the beads while larger molecules and cells, above $60 \mathrm{kDa}$, pass around the beads. In experimental endotoxemia in the rat, haemoadsorption with CytoSorb removed cytokines, reduced nuclear factor (NF)-KB DNA binding in liver cells and improved short-term survival. ${ }^{16}$ In cecal ligation and puncture- induced septic rats haemoadsorption reduced circulating cytokines, improved mean arterial pressure and resulted in increased short-term survival. ${ }^{17}$ CytoSorb has been tested in a multicenter randomised controlled study including 43 patients with sepsis and acute lung injury. ${ }^{18}$ The use of the cytokine-adsorbing column reduced IL-6. Mortality did not differ between the two groups, but the study was not powered for this endpoint. In another study, 37 patients undergoing elective surgery with CPB were randomly assigned to CytoSorb haemoadsorption or a control group. ${ }^{19}$ The primary outcome was difference of cytokine levels (IL-1 $\beta$, IL-6, IL-18, TNF- $\alpha$ and IL-10) within the first five postoperative days. There was no reduction in cytokines level detectable following treatment. Nonetheless, strong interindividual differences in cytokine levels among patients (all low-risk patients) were reported. The authors argued that the inclusion of patients with higher risk might be considered in future studies. ${ }^{19}$ In another randomised study investigating CytoSorb to eliminate cytokines during cardiac surgery on 30 patients, there was no difference in cytokine levels between patients treated with CytoSorb and a control group. ${ }^{20}$ In the REMOVE trial, we address several of these limitations: We assess efficacy of CytoSorb haemoadsorption in a larger high-risk group of IE patients undergoing heart surgery using CPB in a twoarm multicenter, non-blinded, randomised, controlled, group sequential clinical trial. 
METHODS AND ANALYSIS

Objectives

Primary objective

The primary objective of this study is to demonstrate efficacy of a cytokines haemoadsorption device (CytoSorb) in contrast to no device on the development of multiple organ dysfunction syndrome in cardiac surgery patients with IE.

\section{Secondary objectives}

To study the mechanisms of IE-induced vasodilatory shock in patients undergoing cardiac surgery using CPB for IE. This secondary objective is the main focus of the planned interim analysis after 25 patients per study arm at which changes of vasoactive and inflammatory mediator and cell-free DNA (cfDNA) levels will be explored in blood samples.

\section{Endpoints}

The primary confirmatory endpoint of REMOVE is the change in mean total SOFA ( $\triangle$ SOFA) score between the mean total postoperative SOFA score and the SOFA score 24 hours before surgery. The SOFA score is measured on a scale ranging from 0 to 4 for each of six organ systems, with an aggregate score from 0 to 24 and higher scores indicating more severe organ dysfunction (online supplementary file 4) ${ }^{21}$ The mean total postoperative SOFA score will be assessed from the first postoperative day until discharge from the ICU or intermediate care (maximally to the ninth postoperative day). The mean total SOFA score is a well-established endpoint used in a number of previous clinical trials in sepsis ${ }^{22} 23$ and can be used as surrogate for the assessment of short-term mortality. ${ }^{24}$

The secondary endpoints of the study are as follows:

- 30-day mortality rate defined as mortality, in the hospital or anywhere after discharge, within 30-day postoperative.

- Changes in vasoactive and inflammatory mediators and cfDNA levels in the blood samples at start of surgery (skin incision), 30 and $60 \mathrm{~min}$ after starting $\mathrm{CPB}$, at the end of CPB and 24 hours after surgery (skin closure).

- SOFA subscores operationalised as the primary endpoint.

- Cumulative incidence of stroke within 30 days after surgery.

- Duration of mechanical ventilation, vasopressor and renal replacement therapy within 30 days after surgery.

- Length of in-hospital and ICU stay.

\section{Study design}

This study is designed as a multicenter, non-blinded, randomised, controlled, group sequential clinical trial with two groups designed for assessing superiority. Figure 2 shows the flowchart of the study. In the experimental study arm the CytoSorb haemoadsorption device will be integrated into the $\mathrm{CPB}$ during cardiac surgery as shown in online supplementary figure 1 . Patients in the control group will be treated according to the standard of care (no CytoSorb).

We will perform a planned interim analysis after $2 \times 25$ patients focusing on an explorative comparison of vasoactive and inflammatory mediators and cfDNA levels in the interventional and control groups. The second aim of the interim analysis is to check feasibility of recruitment during the planed study period. These 50 patients will be part of the overall analysed population (a pococktype group sequential design, details below). The results of the interim evaluation of the $\Delta$ mean SOFA score, the primary outcome of the study, will only be made available to the data monitoring safety committee.

\section{Time schedule and study duration}

The study duration is planned as 36 months: 24 months of recruitment and 1 month for follow-up and another 6 months for data analysis and publication. The first patient's first visit is planned for the third-quarter (Q3) / 2017. Interim analysis with $2 \times 25$ patients is planned for the end of Q1/2018. Accordingly, last patient's first visit shall be reached Q2/2019 and last patient's last visit in Q3/2019. The final report and publication should be available in Q2/2020.

\section{Study population}

Patients diagnosed with IE according to the modified Duke criteria $^{25}$ undergoing cardiac surgery using CPB.

\section{Inclusion criteria}

- Infective endocarditis according to the modified Duke criteria with an indication for surgery in accordance with the European Guidelines for IE treatment. ${ }^{26}$

- Age $\geq 18$.

- Signed informed consent.

\section{Exclusion criteria}

- Low-risk patients with European System for cardiac operative risk evaluation (EuroScore II) $\leq 3$.

- Current participation in another interventional trial.

- Pregnancy.

- Current immunosuppressive or immunomodulatory therapy (with dosing of glucocorticoids over cushing threshold).

- Previous participation in the REMOVE study.

\section{Obtaining informed consent}

The nature of the study must be explained to each subject (or legally authorised representative) before inclusion in the study. Obtaining of informed consent will then be carried out according to $\S 28$ of the Declaration of Helsinki (online supplementary file 3).

\section{Screening and randomisation}

All patients with IE referred to cardiac surgery in the participating centres will be screened. Patients will be 1:1 randomised into one of the two treatment groups stratified by centre. 


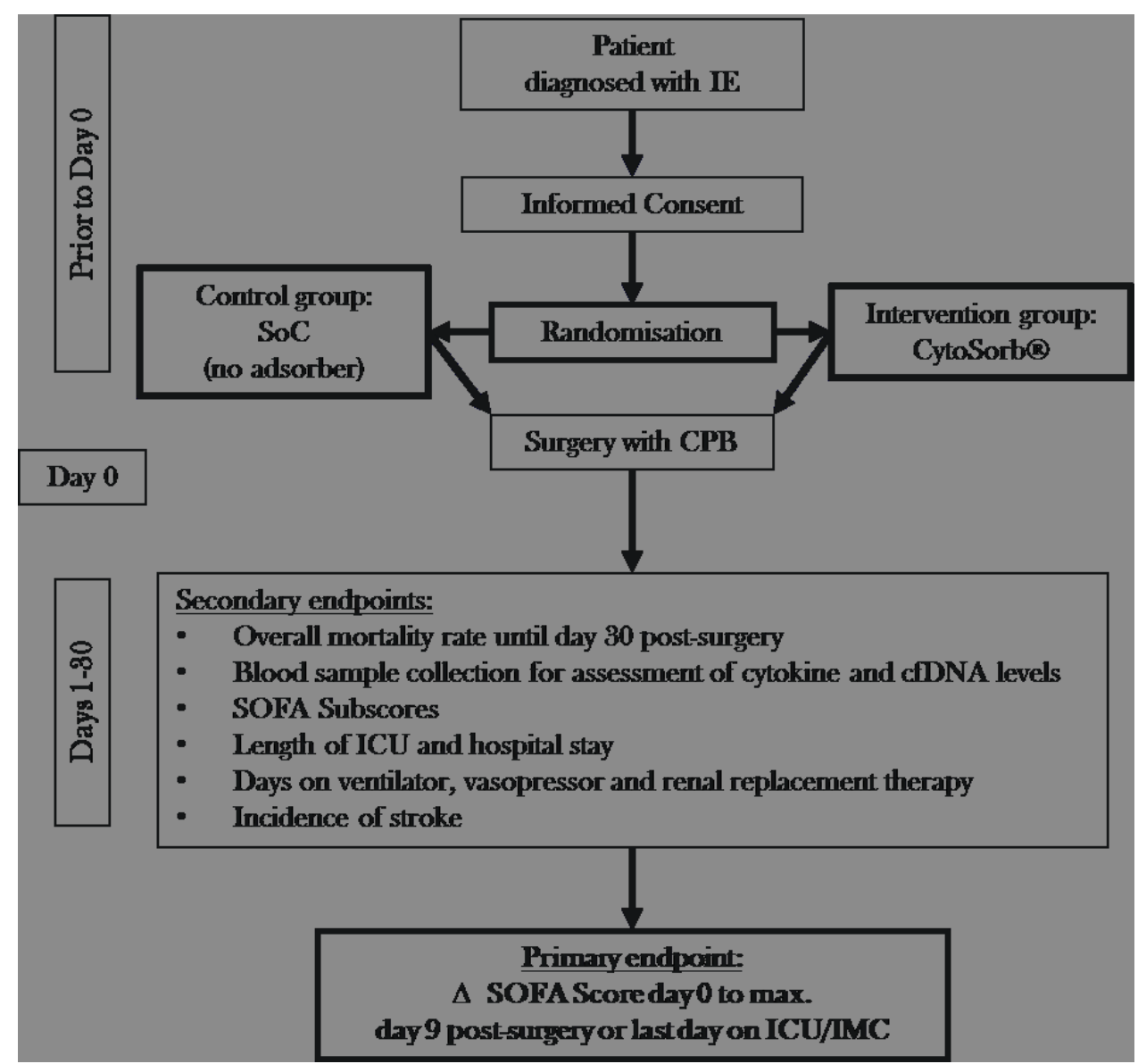

Figure 2 Flowchart of the study procedure. CPB, cardiopulmonary bypass; ICU, intensive care unit; IE, infective endocarditis; IMC, intermediate care unit; SoC, standard of care.

\section{Frequency and scope of study visits}

Table 1 shows the study visits. Sample collection for cytokines measurement will be done at skin incision, 30 and 60 min after starting CPB, at the end of CPB and 24 hours after surgery (only for the first 25 patients in each study arm). Sample collection for cfDNA will be done for the first five patients in each study arm only at the study site of the Jena University Hospital at skin incision, $60 \mathrm{~min}$ after starting CPB and 24 hours after surgery. SOFA score will be assessed within 24 hours before surgery and from the first postoperative day until discharge from the ICU or intermediate care (maximally to the ninth postoperative day). Follow-up of patients will be done on the 30th postoperative day.

\section{Cytokine and cfDNA measurements}

All blood samples for external partners will be taken during surgery and 24-hour post-surgery using a central venous catheter. The following vasoactive and inflammatory mediators will be examined:

- IL-1beta, IL-6, IL-10, IL-18 and TNF- $\alpha$, procalcitonin (PCT), C-reactive protein (CRP).

- C-terminal proendothelin-1 (CT-proET-1), midregional pro-Adrenomedullin(MR-proADM), copeptin pro-Arginine Vasopressin (CT-proAVP), midregional pro-Atrial natriureticPeptide (MR-proANP).
The measurements will be carried out centrally in the laboratory of the external cooperation partner B.R.A.H.M.S (part of ThermoFisher Scientific).

Microbial cfDNA analysis and microbial transcriptome analysis will be carried out at the Fraunhofer Institute for Interfacial Engineering and Biotechnology, Department of Molecular Biotechnology/Functional Genomics Stuttgart, Germany. Blood sampling for microbial transcriptome analysis will only be conducted in $2 \times 5$ patients in Jena as part of a routine blood sampling.

\section{Possible complications and/or risks}

No additional risks for the patients due to study participation are expected. ${ }^{1927} 28$ For the assessment of safety of the study, a focus will be on the documentation of the following events:

- Death.

- Safety of the medical device:

- Breakage of the medical device.

- Malfunction of the medical device.

- Inadequacy in labelling or the instructions for use.

- Intraoperative and postoperative complications.

- Renal replacement therapy.

- Mechanical ventilation.

- Abnormal laboratory values (only laboratory values assessed for SOFA score). 
Table 1 Frequency and scope of REMOVE study visit

Time point

\begin{tabular}{|c|c|c|c|c|c|c|c|c|c|c|}
\hline \multirow[b]{2}{*}{ Flowchart } & \multicolumn{10}{|c|}{ Time point } \\
\hline & $\begin{array}{l}\text { Within } \\
24 \text { hours } \\
\text { before } \\
\text { surgery }\end{array}$ & $\begin{array}{l}\text { Start } \\
\text { surgery } \\
\text { (=skin } \\
\text { incision) }\end{array}$ & $\begin{array}{l}30 \\
\text { min } \\
\text { after } \\
\text { start } \\
\text { CPB }\end{array}$ & $\begin{array}{l}60 \mathrm{~min} \\
\text { after } \\
\text { start } \\
\text { CPB }\end{array}$ & $\begin{array}{l}\text { End } \\
\text { of } \\
\text { CPB }\end{array}$ & $\begin{array}{l}\text { Day } 0 \text { (end } \\
\text { of surgery } \\
\text { to start first } \\
\text { complete } \\
\text { day after } \\
\text { surgery) }\end{array}$ & $\begin{array}{l}\text { Day } 1 \text { (sample } \\
\text { taking } 24 \text { hours } \\
\text { postsurgery=24 } \\
\text { hours after skin } \\
\text { closure) }\end{array}$ & $\begin{array}{l}\text { Day } 2 \text { to } \\
\text { max. day } \\
9 \text { after } \\
\text { surgery or } \\
\text { last day } \\
\text { on ICU/ } \\
\text { IMC }\end{array}$ & $\begin{array}{l}\text { Discharge } \\
\text { from ICU/ } \\
\text { hospital }\end{array}$ & $\begin{array}{l}\text { 30-day } \\
\text { post } \\
\text { surgery }\end{array}$ \\
\hline $\begin{array}{l}\text { Check inclusion criteria; } \\
\text { Informed consent; } \\
\text { randomisation; pregnancy } \\
\text { test; demographic data }\end{array}$ & $x$ & & & & & & & & & \\
\hline $\begin{array}{l}\text { Operative risk assessment } \\
\left(\text { EuroScore }^{*}\right)\end{array}$ & $x$ & & & & & & & & & \\
\hline Duke criteria & $x$ & & & & & & & & & \\
\hline $\begin{array}{l}\text { Cardiac status incl. } \\
\text { endocarditis, SIRS, risk } \\
\text { factors, organ dysfunction }\end{array}$ & $x$ & & & & & & & & & \\
\hline $\begin{array}{l}\text { Charlson comorbidity } \\
\text { assessment } †\end{array}$ & $x$ & & & & & & & & & \\
\hline Concomitant medication $\ddagger$ & $x$ & & & & & & & & & \\
\hline $\begin{array}{l}\text { Microbiology and } \\
\text { antimicrobial treatment } \ddagger \S\end{array}$ & $x$ & & & & & & & & & \\
\hline Blood culture testing $\ddagger$ 凤 & $x$ & & & & & & & & & \\
\hline $\begin{array}{l}\text { Brain natriuretic peptide, } \\
\text { troponin and liver values } \neq\end{array}$ & $x$ & & & & & & & & & \\
\hline Neurological status $\ddagger$ & $x$ & & & & & & & & & \\
\hline $\begin{array}{l}\text { Organ dysfunction } \\
\text { assessment (SOFA) }\end{array}$ & $x$ & & & & & $x$ & $x$ & $x$ & & \\
\hline $\begin{array}{l}\text { Blood sampling for mediator } \\
\text { profiling }^{\star \star}\end{array}$ & & $x$ & $x$ & $x$ & $x$ & & $x$ & & & \\
\hline $\begin{array}{l}\text { Blood sampling for cfDNA } \\
\text { profiling/transcriptome } \\
\text { analysis }{ }^{\star \star}\end{array}$ & $x$ & $x$ & & $x$ & & & $x$ & & & \\
\hline Valve tissue sampling †† & & & $x$ & & & & & & & \\
\hline $\begin{array}{l}\text { Details of surgery and CPB } \\
\text { incl. complications }\end{array}$ & & & & & $x$ & $x$ & $x$ & & & $x$ \\
\hline Incidence of stroke & & & & & & & & & & $x$ \\
\hline $\begin{array}{l}\text { Length of ICU and in- } \\
\text { hospital stay }\end{array}$ & & & & & & & & & $x$ & $x$ \\
\hline $\begin{array}{l}\text { Total days on ventilation, } \\
\text { vasopressor and renal } \\
\text { replacement therapy }\end{array}$ & & & & & & & & & & $x$ \\
\hline Mortality & & & & & & & & & $x$ & $x$ \\
\hline $\begin{array}{l}\text { Blood sampling for MinEd } \\
\text { study } \neq \neq\end{array}$ & & $x$ & & & & & & & & \\
\hline $\begin{array}{l}\text { Cardiovascular incidents or } \\
\text { fatal events }\end{array}$ & & & & & & & $X$ & & & \\
\hline Protocol deviations & & & & & & & $X$ & & & \\
\hline
\end{tabular}

Continued 
Time point

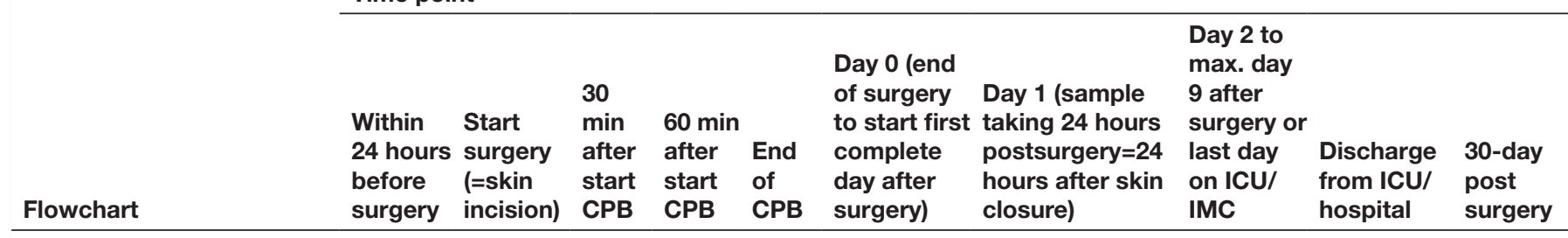

*According to http://www.euroscore.org/calc.html.

†According to http://www.fpnotebook.com/prevent/Exam/ChrlsnCmrbdtylndx.htm.

$\ddagger$ Concomitant medication, antimicrobial treatment, blood culture testing, additional liver values, neurological status: if and as far as indicated.

Concomitant Medication: only immunomodulating therapies.

$\S$ Antimicrobial treatment: substance, application, dose, duration.

१Blood culture testing: time point blood sampling, infectious agent, growing time, resistance.

**Blood sampling only of the first 50 patients for interim.

$\dagger+$ Valve tissue sampling (incl. pathological examination) will only be done if infected tissue is removed during surgery.

¥¥Blood sampling includes $4.9 \mathrm{~mL}$ serum. See section five for further information on MinEd study.

$\mathrm{CPB}$, cardiopulmonary bypass; ICU, intensive care unit; IMC, intermediate care unit; SIRS, systemic inflammatory response syndrom; SOFA,

sequential organ failure assessment.

Any of the above-mentioned adverse event (AE) is considered as serious adverse event (SAE) if it is directly or indirectly caused, may have caused in the past or may cause in the future death or a serious aggravation of the state of health of a patient, user or another person without taking into consideration if the incident was caused by the medical device. The events will be recorded from the moment the medical device is unpacked for surgery until follow-up at day 30 post-surgery.

\section{Statistical considerations and methods \\ Sample size}

Sample size calculations were performed for the primary outcome of $\Delta$ mean SOFA score until day 9 postsurgery. The sample size calculation was done for a pocock-type group sequential design with a planned interim analysis for $2 \times 25$ patients ( $20 \%$ of the total sample size) and a final analysis. It should be noted that the focus of the interim analysis is exploring perioperative plasma profiles of cytokines and vasoactive mediators. The study is designed as a group sequential study in order to be able to test the primary endpoint for superiority at the interim and final analysis. The null hypothesis states that there is no difference between study groups regarding the primary outcome (ie, H0: $\mu 1=\mu 2$ ). Therefore the two-sided alternative hypothesis is $\mathrm{H} 1: \mu 1 \neq \mu 2$. A claim in favour of superiority for the experimental group can be made if $\mathrm{HO}$ can be rejected and if the direction of the effect is in favour of the experimental group. Data from previous studies $^{22} 23$ have shown that a 1.4-point lower SOFA score in the intervention group would be of clinical relevance. We assume a common SD of 3.8 points which results in a standardised effect size of $0.368 \mathrm{SD}^{29}$ To achieve $80 \%$ power at an overall two-sided significance level of $\alpha=5 \%$ while including an interim analysis after $2 \times 25$ patients $(\alpha 1=0.0147)$ and a final analysis $(\alpha 2=0.0378), 125$ patients need to be included per study arm (two-sided group-sequential z-test; nQuery Advisor V.7.0 Statistical Solutions). Based on a previous study, ${ }^{22}$ a drop-out rate of
$15 \%$ is expected, leading to a total of $296(2 \times 148)$ patients that need to be randomised.

\section{Statistical analyses}

The analysis of the primary outcome will be a comparison of the experimental group with CytoSorb adsorber and the control group with standard care with regard to differences in mean total SOFA score until day 9 postsurgery. Note that we consider a two-sided test with $\alpha=0.05(\alpha 1=0.0147(2 \times 25$ patients) and $\alpha 2=0.0378$ (final analysis)), as both superiority of the experimental and superiority of the control group are of interest (ie, a potential harm of the device). The confirmatory analysis on the intention-to-treat analysis set will be performed by a linear mixed model including surgeon and baseline SOFA as fixed effect covariates and centre as random effect. The null hypothesis can be rejected if the $\mathrm{p}$ value related to the Wald test statistic for the treatment effect is equal or smaller than $\alpha 1$ or $\alpha 2$. We will perform explorative sensitivity analysis for the primary outcome such as analyses in the per-protocol analysis set and worst/ best-case scenario analyses in case of missing data on the primary outcome.

All secondary analyses will be done exploratively, that is, without adjustment for multiplicity. We will use adequate standard descriptive and inferential statistical techniques. To be more specific for the changes in vasoactive and inflammatory mediator and cfDNA levels at the interim analysis we will follow the preclinical sepsis models by Peng et $a l^{17}$ We expect a group difference in intraindividual changes of either IL-1 $\beta$, IL- 6 or IL-10 after $60 \mathrm{~min}$, and at the end of CPB. At least one of these three comparisons should meet an explorative significance level of $\alpha_{\text {cyto- }}$ kine $=0.05$. Such a result could serve as an indicator of the mechanistic mode of action of the medical devices and would link the rodent model data of Peng et al to human data. A patient who for any reason (except death) fails to continue in the trial until the last visit is a drop out. 


\section{Methods against bias}

Randomisation and (concealment of) treatment allocation

To address 'concealment of allocation', randomisation will be done centrally. Patients will be randomised, and whoever receives one of the compared treatments is part of the full analysis set (intention-to-treat analysis set). To achieve balanced prognostic factor distributions for the factor centre, we propose to apply a center-stratified 1:1 block randomisation of variable block sizes.

\section{Methods against treatment bias}

This study has a non-blinded study design and assesses real-life treatment strategies. Systematic differences due to differing expertise of participating surgeons will be minimised but cannot be totally ruled out and will be explored in posthoc statistical modelling of their potential effect. All participating sites are certified cardiothoracic centres and have a quality management system. Investigators have to be trained in good clinical practice (GCP). All surgeons should be qualified cardiac surgeons and hold the appropriate national diploma or at least operate under surveillance of a senior cardiac surgeon. Proof of qualification should be given before being acknowledged in participating in the study.

\section{Methods against measurement bias}

At each visit, the occurrence of possible outcomes will be documented in the case report forms (as shown in the online supplementary file 1 ). In addition, all patients will be followed-up after surgery. Finally, monitoring (on-site and central) will be done during the trial by staff of the Center for Sepsis Control and Care and the Center for Clinical Studies, Jena University Hospital.

\section{Data management}

\section{Data assessment/case report forms}

Data acquisition will be done via web application into the study management software OpenClinica. The software meets the regulatory requirements (GCP, 21CFR Part11). The data will be entered via encrypted connection in web browser input masks. Each subject will be given an unambiguous patient identification number to ensure pseudonymised data analysis.

\section{ETHICS AND DISSEMINATION}

The study was approved in September 2017 by the institutional review board and ethics committee of the Friedrich Schiller University (No.: 5240-08/17) as well as by the corresponding ethics committee for each participating centre (online supplementary file 2).

\section{Privacy, collection and processing of data}

The data obtained in the course of the study will be treated pursuant to the appropriate Data Protection Law. During the study, subjects will be identified solely by an individual identification code (subject number). Study findings stored on a computer/server will be stored in accordance with local data protection law and will be handled in strictest confidence.

\section{Dissemination}

The results of this study will be published in a renowned international medical journal, irrespective of the outcomes of the study.

\section{DISCUSSION}

CytoSorb is a haemoadsorption medical device which is capable of removing molecules between 5 and $60 \mathrm{kDa}$ including cytokines, and a wide range of inflammatory mediators. However, the efficacy of CytoSorb is still controversial. While experimental studies on animal models have shown encouraging results, ${ }^{16}{ }^{17}$ clinical studies provided conflicting results. ${ }^{20} 273031$ Small patient samples, non-randomised studies, and the inclusion of low-risk patients were limitations that may explain these discrepancies. In REMOVE we are going to investigate the efficacy of CytoSorb by a randomised trial in a larger patient sample with IE with an established clinical confirmatory surrogate endpoint related to organ dysfunction. Demonstrating efficacy of the use of CytoSorb haemoadsorption during CPB in high-risk patients with IE would be a first evidence-based step forward for this difficult-totreat patient population.

\section{Author affiliations}

${ }^{1}$ Department of Cardiothoracic Surgery, Jena University Hospital - Friedrich Schiller University of Jena, Jena, Thuringia, Germany

${ }^{2}$ Center for Sepsis Control and Care, Jena University Hospital - Friedrich Schiller University, Jena, Thuringia, Germany

${ }^{3}$ Department of Neurology, Jena University Hospital - Friedrich Schiller University of Jena, Jena, Thuringia, Germany

${ }^{4}$ Department of Anaesthesiology and Critical Care Medicine, Jena University Hospital - Friedrich Schiller University of Jena, Jena, Thuringia, Germany

${ }^{5}$ Center of clinical studies, Jena University Hospital - Friedrich Schiller University of Jena, Jena, Thüringen, Germany

${ }^{6}$ Institute of Medical Statistics, Computer and Data Sciences, Jena University Hospital - Friedrich Schiller University, Jena, Thuringia, Germany

${ }^{7}$ Center for Infectious Diseases and Infection Control, Jena University Hospital Friedrich Schiller University, Jena, Thuringia, Germany

Twitter Andre Scherag @ScheragAndre

Acknowledgements We would like to thank Mrs Cornelia Eichhorn for helping in preparing the protocol and Mrs Wibke Wetzker for editorial assistance.

Collaborators B.R.A.H.M.S (part of ThermoFisher Scientific), Hennigsdorf, Germany. Fraunhofer Institute for Interfacial Engineering and Biotechnology, Department of Molecular Biotechnology/Functional Genomics, Stuttgart, Germany. University Hospital Cologne, Clinic and Policlinics for Heart and Thoracic Surgery. University Hospital Essen, Clinic of Thoracic and Cardiovascular Surgery. University Heart Center Freiburg-Bad Krozingen. University Hospital Ulm, Clinics of Heart, Thoracic and Cardiovascular Surgery. Berufsgenossenschaftliches Universitätsklinikum Bergmannsheil gGmbH (Bergmannsheil University Hospitals), Clinic for Heart and Thoracic Surgery. Leipzig Heart Center, University Hospital for Heart Surgery. Dresden Heart Center, University Hospital at the Technical University Dresden, Clinic for Heart Surgery. University Hospital Düsseldorf, Clinic for Cardiovascular Surgery. Mid-German Heart Center, University Hospital Halle (Saale), Clinic for Cardiac und Thoracic Surgery. Heart and Diabetes Center NRW, Bad Oeynhausen, Clinic for Thoracic and Cardiovascular Surgery. Heart Center Brandenburg, Immanuel Clinic Bernau (Berlin). University Hospital Bonn, Clinic and Policlinic for Heart Surgery. Data safety monitoring board (DSMB): The DSMB is responsible for approval of protocol, interim review of the study, and monitoring 
of safety and efficacy data. Members of this board are: Matthias Loebe. Miami Transplant institute, Memorial Jackson Health System, University of Miami. John A. Kellum, Department of Critical Care Medicine, University of Pittsburgh. Peter U. Heuschmann, Institute for Clinical Epidemiology and Biometry, University of Würzburg.

Contributors MD is the principal investigator. MD, SP, FMB, AS and CS wrote the protocol. AS was involved in the design and sample-sized considerations; $T L$ is the responsible biometrician. TD, MB, FMB, AG, AS and SH are scientific advisors who participated in reviewing the protocol. SP is the project manager and monitor. MD and IV are responsible for patients' recruitment at theUniversity Hospital of Jena. All coauthors read and proved the final manuscript.

Funding This study is funded partly within the funding of the Integrated Research and Treatment Center (Integriertes Forschungs- und Behandlungszentrum; IFB) 'Sepsis und Sepsisfolgen' (Sepsis and consequences of sepsis) by the German Federal Ministry of Education and Research (Funding code: 01E01502; Funding of: Case payments, personnel costs, material costs, travel expenses, fees and charges). CytoSorbents Europe GmbH provides the CytoSorb absorbers required during the study free of charge and provides further funding (laboratory analyses by B.R.A.H.M.S. and Fraunhofer IGB, sample shipping, investigator meetings and working student).

Competing interests FMB reports grants and personal fees from CytoSorbents Europe,outside the submitted work.

Patient and public involvement Patients and/or the public were not involved in the design, or conduct, or reporting, or dissemination plans of this research.

Patient consent for publication Not required.

Provenance and peer review Not commissioned; externally peer reviewed.

Open access This is an open access article distributed in accordance with the Creative Commons Attribution Non Commercial (CC BY-NC 4.0) license, which permits others to distribute, remix, adapt, build upon this work non-commercially, and license their derivative works on different terms, provided the original work is properly cited, appropriate credit is given, any changes made indicated, and the use is non-commercial. See: http://creativecommons.org/licenses/by-nc/4.0/.

\section{ORCID iDs}

Mahmoud Diab http://orcid.org/0000-0003-1529-6046

Christoph Sponholz http://orcid.org/0000-0002-1746-7024

Andre Scherag http://orcid.org/0000-0002-9406-4704

\section{REFERENCES}

1 Prendergast BD, Tornos P. Surgery for infective endocarditis: who and when? Circulation 2010;121:1141-52.

2 Tleyjeh IM, Abdel-Latif A, Rahbi $\mathrm{H}$, et al. A systematic review of population-based studies of infective endocarditis. Chest 2007;132:1025-35.

3 Yew HS, Murdoch DR. Global trends in infective endocarditis epidemiology. Curr Infect Dis Rep 2012;14:367-72.

4 Murdoch DR, Corey GR, Hoen B, et al. Clinical presentation, etiology, and outcome of infective endocarditis in the 21st century: the International collaboration on Endocarditis-Prospective cohort study. Arch Intern Med 2009:169:463-73.

5 Gálvez-Acebal J, Rodríguez-Baño J, Martínez-Marcos FJ, et al. Prognostic factors in left-sided endocarditis: results from the Andalusian multicenter cohort. BMC Infect Dis 2010;10:17.

6 Gelsomino S, Maessen JG, van der Veen F, et al. Emergency surgery for native mitral valve endocarditis: the impact of septic and cardiogenic shock. Ann Thorac Surg 2012;93:1469-76.

7 Musci M, Weng Y, Hübler M, et al. Predictors of early mortality in patients with active infective native or prosthetic aortic root endocarditis undergoing homograft aortic root replacement. Clin Res Cardiol 2009;98:443-50.

8 Mourvillier B, Trouillet J-L, Timsit J-F, et al. Infective endocarditis in the intensive care unit: clinical spectrum and prognostic factors in 228 consecutive patients. Intensive Care Med 2004;30:2046-52.

9 Diab M, Guenther A, Scheffel P, et al. Can radiological characteristics of preoperative cerebral lesions predict postoperative intracranial haemorrhage in endocarditis patients? Eur J Cardiothorac Surg 2016;49:e119-26.
10 Boyle EM, Pohlman TH, Johnson MC, et al. Endothelial cell injury in cardiovascular surgery: the systemic inflammatory response. Ann Thorac Surg 1997;63:277-84.

11 Werdan K, Dietz S, Löffler B, et al. Mechanisms of infective endocarditis: pathogen-host interaction and risk states. Nat Rev Cardiol 2014;11:35-50.

12 Hotchkiss RS, Karl IE. The pathophysiology and treatment of sepsis. N Engl J Med 2003;348:138-50.

13 Bustamante J, Arévalo A, Tamayo E, et al. Cytokine profiles linked to fatal outcome in infective prosthetic valve endocarditis. APMIS 2014;122:526-9.

14 Ekdahl C, Broqvist M, Franzén S, et al. II-8 and tumor necrosis factor alpha in heart valves from patients with infective endocarditis. Scand $J$ Infect Dis 2002;34:759-62.

15 Diab M, Tasar R, Sponholz C, et al. Inflammatory and vasoactive mediator profiles during valvular surgery for infective endocarditis versus noninfectious valvular heart disease. Thorac Cardiovasc Surg 2018;66:S1-110.

16 Kellum JA, Song M, Venkataraman R. Hemoadsorption removes tumor necrosis factor, interleukin-6, and interleukin-10, reduces nuclear factor-kappaB DNA binding, and improves short-term survival in lethal endotoxemia. Crit Care Med 2004;32:801-5.

17 Peng Z-Y, Carter MJ, Kellum JA. Effects of hemoadsorption on cytokine removal and short-term survival in septic rats. Crit Care Med 2008;36:1573-7.

18 Schädler D, Porzelius C, Jörres A, et al. A multicenter randomized controlled study of an extracorporeal cytokine hemoadsorption device in septic patients. Critical Care 2013;17:P62

19 Bernardi MH, Rinoesl H, Dragosits K, et al. Effect of hemoadsorption during cardiopulmonary bypass surgery - a blinded, randomized, controlled pilot study using a novel adsorbent. Crit Care 2016;20:96

20 Poli EC, Alberio L, Bauer-Doerries A, et al. Cytokine clearance with CytoSorb $®$ during cardiac surgery: a pilot randomized controlled trial. Crit Care 2019;23:108.

21 Vincent JL, Moreno R, Takala J, et al. The SOFA (sepsis-related organ failure assessment) score to describe organ dysfunction/ failure. on behalf of the Working group on sepsis-related problems of the European Society of intensive care medicine. Intensive Care Med 1996;22:707-10.

22 Brunkhorst FM, Engel C, Bloos F, et al. Intensive insulin therapy and pentastarch resuscitation in severe sepsis. $N$ Engl J Med 2008;358:125-39.

23 Brunkhorst FM, Welte T, Sepsis SK. MAXSEP Study - prospective, randomized, open label, multicenter Study on the Effect of an empirical antibiotic Monotherapy with Meropenem versus a Combination Therapy with Moxifloxacin on Organ Function in Patients with severe Sepsis and septic Shock. Infection 2012;40:30-1.

24 McGhee JD, Fukushige T, Krause MW, et al. ELT-2 is the predominant transcription factor controlling differentiation and function of the C. elegans intestine, from embryo to adult. Dev Biol 2009;327:551-65.

25 Li JS, Sexton DJ, Mick N, et al. Proposed modifications to the Duke criteria for the diagnosis of infective endocarditis. Clin Infect Dis 2000;30:633-8.

26 Habib G, Lancellotti P, Antunes MJ, et al. 2015 ESC guidelines for the management of infective endocarditis: the task force for the management of infective endocarditis of the European Society of cardiology (ESC). endorsed by: European association for CardioThoracic surgery (EACTS), the European association of nuclear medicine (EANM). Eur Heart $J$ 2015;36:3075-128.

27 Schädler D, Pausch C, Heise D, et al. The effect of a novel extracorporeal cytokine hemoadsorption device on IL-6 elimination in septic patients: a randomized controlled trial. PLoS One 2017;12:e0187015

28 Träger K, Skrabal C, Fischer G, et al. Hemoadsorption treatment of patients with acute infective endocarditis during surgery with cardiopulmonary bypass - a case series. Int J Artif Organs 2017;40:240-9.

29 Brunkhorst FM, Oppert M, Marx G, et al. Effect of empirical treatment with moxifloxacin and meropenem vs meropenem on sepsis-related organ dysfunction in patients with severe sepsis: a randomized trial. JAMA 2012;307:2390-9.

30 Friesecke S, Stecher S-S, Gross S, et al. Extracorporeal cytokine elimination as rescue therapy in refractory septic shock: a prospective single-center study. J Artif Organs 2017;20:252-9.

31 Kogelmann K, Jarczak D, Scheller M, et al. Hemoadsorption by CytoSorb in septic patients: a case series. Crit Care 2017;21:74. 